\title{
Partner support as a mediator of the relationship between prenatal concerns and psychological well-being in pregnant women
}

\begin{abstract}
BACKGROUND
Pregnant women's psychological well-being affects their emotional state, which in turn has a significant impact on fetal development, the course of labor, and the mother's adaptation in the postpartum period. Social support, especially partner support, is proven to have a protective effect against stress, worries, and concerns that occur in pregnancy. The main objective of this study was to investigate whether support received from the partner mediates the relationship between pregnant women's prenatal concerns and psychological well-being.
\end{abstract}

\section{PARTICIPANTS AND PROCEDURE}

The study involved 137 pregnant women aged 18-40 years. Received partner support was measured with a subscale (Actually Received Social Support) of the Polish version of the Berlin Social Support Scales (BSSS). Furthermore, the Concerns of Pregnant Women Scale (POC) and Ryff's Psychological Well-Being Scales (PWB) were used. The demographic and pregnancy-related variables were controlled.

RESULTS

The obtained results reveal prenatal concerns, received partner support and psychological well-being to be cor- related. Partner support was the strongest predictor of psychological well-being in five domains: environmental mastery, purpose in life, personal growth, positive relations with others and self-acceptance. What is more, statistical analyses confirmed the significance of partner support in mediating relationships between prenatal concerns and two dimensions of pregnant women's well-being: environmental mastery and purpose in life.

\section{CONCLUSIONS}

Our analyses confirm the results obtained so far in studies on the meaning of social support, particularly that received from a partner, for the health and well-being of pregnant women. We found that received partner support fully mediated the relationship between the concerns of pregnant women and some areas of their psychological well-being. Due to the received partner support, pregnant women's prenatal concerns cease to affect their beliefs about the meaning of life, feeling of fulfillment of important life tasks, and beliefs about their ability to cope with the world.

KEY WORDS

pregnant women; psychological well-being; prenatal concerns; partner support 


\section{BACKGROUND}

The prenatal period has been a subject of numerous studies in psychology, with researchers' attention focused on the risk of obstetric failures, risk to maternity and the child's health, coping with stress, and handling depression in pregnant women as well as the development of a parental bond with the child (cf. Bidzan, Bieleninik, Zadolska, \& Salwach, 2009; Guardino \& Dunkel-Schetter, 2014; Accortt, Cheadle, \& Dunkel-Schetter, 2015; Yim, Tanner Stapleton,
Michalina Ilska, Hanna

Przybyła-Basista Guardino, Hahn-Holbrook, \& Dunkel-Schetter, 2015). The undertaken lines of research cover seeking factors that determine: (a) the establishment of an emotional bond with the unborn baby during pregnancy (e.g., Bidzan et al., 2009; Bieleninik, Preis, \& Bidzan, 2010; Pawlicka, Chrzan-Dętkoś, \& Lutkiewicz, 2013; Mass, Vreeswijk, de Cock, Rijk, \& van Bakel, 2012); (b) the experience of stress and its effect on the physical health of pregnant women and infants (e.g., DaCosta, Larouche, Dritsa, \& Brender, 1999; DiPietro, 2004); (c) the psychological well-being of a pregnant woman in relation to analysis of mental health resources and social resources (e.g., Dyrdal, Røysamb, Bang Nes, \& Vittersø, 2010; Sieber, Germann, Barbir, \& Ehlert, 2006; Rini, Killingsworth, Dunkel-Schetter, Wadhwa, \& Sandman, 1999; Yali \& Lobel, 2002); (d) the process of adapting to parental roles (with particular focus on motherhood) and disturbances within this process in the form of adaptive problems occurring in pregnancy and after childbirth (e.g., Bielawska-Batorowicz \& Kossakowska-Petrycka, 2006; Ilska \& PrzybyłaBasista, 2014, 2015; Kaźmierczak, Kiełbratowska, \& Karasiewicz, 2015; Nishimura, Fujita, Katsuta, Ishihara, \& Ohashi, 2015).

The stress a pregnant woman is exposed to due to adaptive difficulties, everyday challenges or a threat to pregnancy determines emotions that arise in such a situation, which may reciprocally affect the individual's cognitive assessment of the situation and hinder the adaptive process. Each pregnancy, including those not encumbered with social and obstetric risks, is a stressful situation considered by some researchers as a critical event related to psychological distress. This stems from the necessity to readapt to life changes regarding finances, relations with the partner, family obligations or professional career (Dulude, Wright, \& Belanger, 2000). Studies conducted by DaCosta et al. (1999) proved that pregnant women experience stress and anxiety of varying intensity depending on the trimester of pregnancy. Stress and negative emotions in pregnancy are risk factors for obstetric complications during pregnancy and delivery, disruptions in the process of adapting to motherhood, postpartum depression or even premature birth or low birth weight (Accort et al., 2015; DiPietro, 2004; Dunkel-Schetter \& Tarner, 2012; Lobel et al., 2008).
The emotion most commonly experienced by pregnant women is anxiety, which pertains to the child's health and life, the successful end of pregnancy, pregnant women's own health, future fertility, future parenthood, relations with the partner, changes in physical appearance, and labor pain (DaCosta et al., 1999; Lobel et al., 2008; DiPietro, 2004). An individual's worry and concern involve a chain of thoughts and images, and are usually focused on uncertain future events. Though concerns, worry and anxiety are closely related constructs, they are distinguished by researchers. Anxiety is defined as a psychological and physiological state characterized by cognitive, somatic, emotional, and behavioral components, whereas concerns and worry are limited to the cognitive component of anxiety (see Puente, Monge, Abella'n, \& Morales, 2011).

Worry related to the course of pregnancy, particularly concerning one's own health and the child's health, is a common phenomenon among pregnant women and may be significantly exacerbated in some cases (Fava et al., 1990). Melender and Lauri (1999) distinguished objects of fears experienced by pregnant women, which pertained to the mother's health and the course of pregnancy (e.g., possibility of miscarriage; unattractive appearance during pregnancy), childbirth (e.g., possible complications, caesarean section, labor pain), the baby's health and well-being (e.g., the possibility that the baby may be handicapped), medical staff (e.g., general fears associated with the hospital or mistakes made by hospital staff), and the partner (how the pregnant women's husbands or partners will cope in the delivery room). The women describe their fears by listing various emotions such as worry, concern, sadness, bad conscience, uncertainty, panic, terror, depression, and the feeling of inability to enjoy pregnancy (Melender \& Lauri, 1999). Factors that contribute to increasing fear and worry in pregnant women may include: unsatisfying relationship with their partners, previous obstetrical failures, low socio-economic status, and unemployment (Gourounti, Anagnostopoulos, \& Lykeridou, 2013; Gourounti, Anagnostopoulos, \& Sandall, 2014). Moreover, factors that increase the risk of concerns include loss of previous pregnancies and whether the current pregnancy was planned or not (Ilska, Kołodziej-Zaleska, \& Ilski, 2015).

In the process of managing various stressful situations the key role is played by relational resources that comprise social support. Social support is a kind of social interaction undertaken in a problematic, difficult, stressful or crisis situation. Its main objective is to maintain or decrease the overall level of stress and to overcome the crisis by means of a social interchange of varying content (see Sęk \& Cieślak, 2012). An important role is played here by close interpersonal relations, particularly partnerships. Researchers agree that the most significant source of 
support for a pregnant woman is her partner (Rini, Dunkel-Schetter, Hobel, Glynn, \& Sandman, 2006; Stapleton et al., 2012). It has been shown that partner support - similarly to a younger age of pregnant women - acts as a protective factor that prevents the prenatal concerns from intensifying in a group of women hospitalized due to obstetric complications of pregnancy (Ilska et al., 2015).

In the context of pregnancy, social support plays a significant role by exerting a positive effect on a woman's psychological well-being, whereas a close relation with her partner can be critical (see Ritter et al., 2000). There is increasing evidence from numerous studies that social relations have a positive effect on both physical and psychological well-being of pregnant women (Dunkel-Schetter, Sagrestano, Feldman, \& Killingsworth, 1996; Oakley, 1988). Support may affect the mother during pregnancy by motivating her to engage in positive health behaviors, to change her lifestyle, and to take care of her physical health (Feldman, Dunkel-Schetter, Sandman, \& Wadhwa, 2000).

Researchers are particularly interested in the perceived social support and the received social support. According to research findings (see Norris \& Kaniasty, 1996; Smoktunowicz, Cieślak, \& Żukowska, 2013), perceived support (a belief concerning a subjective feeling of availability of potential sources of support) is a better predictor of an individual's well-being, stress coping and health compared to received support (a conviction pertaining to support actually received in the past, e.g., over the previous month). Although the relation between the received support and the pregnant women's health and well-being has been repeatedly confirmed, the results are not always that inconclusive. Contradictory results have also been obtained, proving an increase of distress in the person who received support (Rini et al., 2006). In their attempt to explain the discrepancies, researchers draw attention to the possibility of the form of support being inadequate in relation to needs, an inappropriate source of help or a threat to self-esteem caused by inadequate help (Norris $\&$ Kaniasty, 1996; Smoktunowicz et al., 2013). Hence, Rini et al. (2006) claim that there is a need for a new conceptualization of social support effectiveness that would account for the assessment of the adequacy of support received by a woman from her partner during pregnancy.

Researchers emphasize that the impact of social support depends on complex mechanisms and correlations between individuals who provide support and those who receive support in the context of a given stressful or crisis situation (see Sęk \& Cieślak, 2012). There are models that explain the mechanisms of how resources affect an individual's health and well-being (cf. Hobfoll, 2002). When examining the impact of stress on health, we may differentiate be- tween a direct and an indirect effect. The direct effect on stressors is based on the assumption that social support has a preventive effect or modifies the perception of stress. Moreover, in our studies we have also tested a hypothesis about an indirect effect exerted by support - the so-called buffering hypothesis - which safeguards a given person against the potentially pathogenic influence of stressful events and takes place following the occurrence of a stressor. Here, the effect of support consists in decreasing the tension experienced by a supported person or changing the way she perceives a situation and herself (Cohen \& Willis, 1985).

Studies on social support in pregnancy have largely pertained to its specific aspects and covered an analysis of the main effects. These confirmed the significant role of social support for the health and well-being of a woman and her child during pregnancy, the possibility of obstetric complications, premature delivery, as well as the health and development of the child after birth (Collins, Dunkel-Schetter, Lobel, \& Scrimshaw, 1993; Ghosh, Wilhelm, Dunkel-Schetter, Lombardi, \& Ritz, 2010; Dunkel-Schetter $\&$ Tanner, 2012). Anxiety and symptoms of depression are higher in pregnant women who have less social support and experience postpartum depression more often (Collins et al., 1993; Ritter et al., 2000; Stapleton et al., 2012).

The number of analyses supporting the buffering effect of social support in pregnant women is low. This effect was observed in an analysis of correlations between an unwanted pregnancy and depression in pregnant women (Dibaba, Fantahun, \& Hindin, 2013), as well as in an analysis of the impact of chronic stress in pregnant women on premature delivery (Ghosh et al., 2010). Apart from being a moderator, social support may serve another indirect effect, namely, that of a mediator in a relationship between stress and the psychological functioning of an individual (Smoktunowicz et al., 2013). Studies on a model explaining the occurrence of postpartum depression with mediation analyses taken into account confirmed the role of satisfaction with social support and self-esteem as partial mediators in the relation between antepartum stress and depressive symptoms (Jesse, Kim, \& Herndon, 2014).

Based on the review of research presented above, it can be assumed that social support, with a particular focus on received support, is such a highly complex phenomenon that it requires undertaking further and more advanced studies in this regard. Although abundant evidence on the direct effect on a pregnant woman's health has been collected, the researchers' interest is still focused on explaining the operation of complex mechanisms of influence, in which social support acts as a mediator or a moderator. Studies using mediation and moderation analyses are a relatively new yet promising direction of
Partner support as a mediator of the relationship 
Michalina Ilska, Hanna

Przybyła-Basista empirical analyses. In this article we have focused on explaining the role played by support received from the partner during pregnancy in mediating the relationship between prenatal concerns of pregnant women and their psychological well-being.

Studies on the well-being of pregnant women have shown that it affects the emotional state of a woman, which is in turn essential for fetal development, the course of delivery and the mother's adaptation in the postpartum period (Dunkel-Schetter et al., 1996; Sieber et al., 2006; Lee, Ayers, \& Hlden, 2012; Accortt et al., 2015). According to studies conducted by Dyrdal et al. (2010), women in general have high life satisfaction throughout pregnancy, with a decrease in satisfaction occurring after the first child's birth, and it remains stable through infancy. It has also been proven that the stress experienced by a pregnant woman has a negative influence on her psychological well-being (PWB) (Zachariah, 1996; Cheng \& Pickler, 2010).

Psychological well-being is a broad concept defined as a cognitive and emotional assessment of one's own life (Diener, Lucas, \& Oishi, 2012). Subjective well-being (SWB) is an assessment of life in the categories of satisfaction and balance between positive and negative affect, whereas PWB involves a given person's perception of his or her engagement in coping with existential challenges of life (Keyes, Shmotkin, \& Ryff, 2002). In line with Ryff's concept (1989), psychological well-being is described by six dimensions: (1) self-acceptance - a positive attitude towards the Self, (2) positive relations with others, (3) autonomy - the capacity to act according to individually established principles, (4) environmental mastery - the ability to cope with the world, (5) purpose in life - the ability of an individual to achieve the meaning of life and to fulfill life tasks, and (6) personal growth - the ability to fulfill one's talent and potential. This concept has been employed in the authors' own empirical research, which shall be subjected to further analysis.

In conclusion, recent psychological considerations have been focused on characterizing the meaning of pregnant women's concerns for their psychological well-being, which has been proven to be linked to the physical and mental health of a mother and her unborn child. In this context, it seems important to ask what is the role of the partner (the child's father) as the closest person in the marital relation (partnership), which by means of affecting the woman can either strengthen or mitigate her anxiety and concerns.

Hence, the main objective of this study was to determine whether support received from the partner mediates the relationship between prenatal concerns and psychological well-being of pregnant women. Specific objectives were as follows: the first aim of the study was to examine relationships between prenatal concerns, partner support and psychological well-being. Another aim of the study was to explore partner support as a potential mediator of the effect exerted by prenatal concerns on psychological well-being of pregnant women.

\section{PARTICIPANTS AND PROCEDURE}

The sample comprised 137 pregnant women (68 in low-risk pregnancy and 69 in high-risk pregnancy) from the south of Poland. Recruitment to the study was conducted among pregnant women admitted to the clinic for gynecological examination and patients staying at the pregnancy pathology ward. The study began in March 2013 and ended in December 2015. The participants were informed about the research objective and granted their informed consent to participate in the study. Participation in the study was voluntary and pregnant women had the right to withdraw from the study at any time. Proceedings for ensuring the participants' anonymity were employed. Each pregnant woman received a set of questionnaires in a separate envelope and was asked to complete and deliver them to the clinic in a sealed envelope at the next visit or when they were ready to give them back to the person conducting the survey.

Over three quarters of the participants, i.e., $77.20 \%$ ( $n=105)$, were expecting their first child (primiparous women). They were aged between 18 and 39 $(M=29.78, S D=4.25)$. Most of the participants were employed ( $77.80 \%$ full-time and $7.40 \%$ part-time) with university education $(68.10 \%)$, married $(78.80 \%)$ or in informal relationships $(21.20 \%)$. The average duration of the respondents' relationships was 4 years $(M=4.02, S D=3.39)$. Nearly all of the participants were in advanced pregnancy, with the majority being in the third trimester $(57.90 \%, n=77)$ or the second trimester of pregnancy $(32.30 \%, n=43)$, and only $9.80 \%(n=13)$ in the first trimester. Nearly one quarter of the participants had previously experienced unplanned pregnancy $(23.50 \%, n=32)$ whereas $15.40 \%$ $(n=21)$ had a history of miscarriage. Nearly one third of the respondents reported conception issues $(29.30 \%$, $n=39$ ). Detailed data are presented in Table 1 .

\section{MEASURES}

Demographics and pregnancy information. In a demographic questionnaire, the respondents were asked to provide information regarding their age, marital status or informal relationship (married, cohabitee), relationship duration and level of education, and to describe their material situation. In a basic pregnancy information questionnaire, the respondents were asked to provide details on pregnancy planning, pregnancy trimester and in cases of high-risk pregnancy also the duration of hospitalization and medical diagnosis. 
Psychological well-being (PWB). The 42-item Psychological Well-Being Scales were developed by Ryff and Keyes (1995). The scale was used to assess six areas of psychological well-being (each consisting of 7 items): autonomy, environmental mastery, personal growth, positive relations with others, purpose in life, and self-acceptance. Respondents rated statements on a scale of 1 to 7, with 1 indicating strong disagreement and 7 indicating strong agreement. Scores for each of the six categories are totaled separately. For each category, a high score indicates that the respondent has mastered a given area of his or her life. Conversely, a low score shows that the respondent struggles to feel comfortable with that particular concept. In this study the Polish version of the PWB was used. The Cronbach $\alpha$ coefficients for the Polish version of the PWB range from .72 to .86 (Krok, 2009), whereas for the reported sample the Cronbach $\alpha$ coefficients range from .51 to .79 .

Received partner support (BSSS). Received partner support was measured with one of the subscales (Actually Received Social Support) of the Polish version of the Berlin Social Support Scales (BSSS - Schwarzer \& Schultz; see Łuszczyńska, Kowalska, Mazurkiewicz, \& Schwarzer, 2006). The 15-item Actually Received Social Support subscale was used in this research with responses ranging from 1 (completely untrue) to 4 (completely true). Higher scores indicated greater received partner support. The Cronbach $\alpha$ coefficient for this subscale was 90 (Łuszczyńska et al., 2006). In the present study the Cronbach $\alpha$ coefficient was 94 .

Prenatal concerns (POC). The 6-item Concerns of Pregnant Women Scale (POC) (Ilska et al., 2015) allows assessment of the intensity of the concerns of pregnant women. The POC was constructed on the basis of available literature and research reports (Ilska et al., 2015). Prenatal concerns are defined by the authors of the questionnaire as the aspects of a pregnant woman that cause her to feel anxious about the future health of herself and her child. These include concerns about biological and psychological changes occurring in the course of pregnancy, delivery and in the postpartum period. Responses range from 0 (no concerns) to 4 (very high concerns). The theoretical distribution of the results ranges from 0 to 24 points. High scores indicate a considerable increase in the concerns experienced by pregnant women. The Cronbach $\alpha$ coefficient for this scale was .71.

Statistical analysis was performed using PS IMAGO 3 SPSS 23. All data (descriptive statistics, correlations and mediation analysis) were obtained using this statistical package. The mediation analysis was conducted in accordance with Baron and Kenny's approach (1986). Initial mediations were tested with six domains of psychological well-being as outcome variables, one predictor variable (prenatal concerns) and one potentially mediating variable (partner support). For all tests the type I error rate was set at $\alpha=.05$.
Table 1

Sample characteristics

\begin{tabular}{lc}
\hline Variable & $n=137$ \\
\hline Demographic & \\
Age $-M(S D)$ & $29.78(4.25)$ \\
Marital status, \% $(n)$ & \\
$\quad$ Married & $78.80(104)$ \\
$\quad$ Cohabiting & $21.20(28)$ \\
Relationship duration $-M(S D)$ & $4.02(3.39)$ \\
Pregnancy information & \\
Pregnancy planning, \% $(n)$ & $79.10(53)$ \\
Primiparous, \% $(n)$ & $77.00(104)$ \\
Miscarriage, $\%(n)$ & $15.40(21)$ \\
Conception issues, \% $(n)$ & $29.30(39)$ \\
\hline
\end{tabular}

\section{RESULTS}

As suggested by Baron and Kenny (1986), several preconditions must be met to determine whether a variable has a mediating effect. These preconditions were assessed with Pearson's correlations among the variables of interest. This analysis allowed us to identify the relevant variables to be introduced in the subsequent regression analyses. In order to examine whether there is a significant correlation between prenatal concerns, received partner support and six dimensions of psychological well-being, Pearson correlation analysis was used. The correlation coefficients of the study variables are presented in Table 2. Pearson correlations showed prenatal concerns to be negatively associated with received partner support $(r=-.20, p=.023)$, environmental mastery $(r=-.22, p=.010)$, and purpose in life $(r=-.22$, $p=.013)$. Prenatal concerns were not significantly correlated with autonomy, personal growth, positive relations with others or self-acceptance. Pearson correlations showed that partner support was positively associated with environmental mastery $(r=.35, p<.001)$, personal growth $(r=.37, p<.001)$, positive relations with others $(r=.40, p<.001)$, purpose in life $(r=.41, p<.001)$ and self-acceptance $(r=.31, p<.001)$. Partner support was not significantly correlated with autonomy.

The following four conditions must be met to establish mediation (Baron \& Kenny, 1986); variables covered in the analyses in successive steps are provided in parentheses. Step 1: the predictor variable (prenatal concerns) is related to the outcome variable (6 dimensions of psychological well-being). Step 2: the predictor variable (prenatal concerns) is related to the potential mediator (partner support). Step 3:
Partner support as a mediator of the relationship 
Table 2

Pearson correlations for all of the study variables

Michalina Ilska, Hanna

Przybyła-Basista

\begin{tabular}{|c|c|c|c|c|c|c|c|c|}
\hline & 1 & 2 & 3 & 4 & 5 & 6 & 7 & 8 \\
\hline 1. POC - Prenatal concerns & 1.00 & & & & & & & \\
\hline 2. BSSS - Partner support & $-0.20^{*}$ & 1.00 & & & & & & \\
\hline 3. PWB - Autonomy & -0.04 & -0.06 & 1.00 & & & & & \\
\hline 4. PWB - Environmental mastery & $-0.22^{*}$ & $0.35^{* *}$ & $0.49^{* *}$ & 1.00 & & & & \\
\hline 5. PWB - Personal growth & -0.12 & $0.37^{* *}$ & 0.14 & $0.53^{* *}$ & 1.00 & & & \\
\hline 6. PWB - Positive relations with others & -0.12 & $0.40^{* *}$ & $0.18^{*}$ & $0.63^{* *}$ & $0.35^{* *}$ & 1.00 & & \\
\hline 7. PWB - Purpose in life & $-0.22^{*}$ & $0.41^{* *}$ & $0.21^{*}$ & $0.64^{* *}$ & $0.61^{* *}$ & $0.57^{* *}$ & 1.00 & \\
\hline 8. PWB - Self-acceptance & -0.12 & $0.31^{* *}$ & $0.43^{* *}$ & $0.78^{* *}$ & $0.56^{* *}$ & $0.59^{* *}$ & $0.64^{* *}$ & 1.00 \\
\hline
\end{tabular}

the mediator (partner support) is related to the outcome variable (6 dimensions of psychological well-being) and this relation remains once the predictor variable (prenatal concerns) is included in the model. Step 4: the relation between the predictor variable (prenatal concerns) and the outcome variable (6 dimensions of psychological well-being) becomes insignificant once the effect of the mediator (partner support) is controlled.

In the case of the discussed sample, only two domains of psychological well-being met these criteria, namely, environmental mastery and purpose in life. (Step 1) Pregnancy concerns met the first requirement by showing a significant relationship with the mediator - partner support $(\beta=-.20, p=.023)$. (Step 2) Only two dimensions of psychological well-being, environmental mastery $(\beta=-.22, p=.010)$ and purpose in life $(\beta=-.22, p=.013)$, were considered outcome variables in the mediation analysis because of their relationship with prenatal concerns. Autonomy, personal growth, positive relations with others and self-acceptance were not related to prenatal concerns. (Step 3) Partner support was associated with five dimensions of psychological well-being environmental mastery $(\beta=.35, p<.001)$, purpose in life $(\beta=.41, p<.001)$, personal growth $(\beta=.37$, $p<.001)$, positive relations with others $(\beta=.40$, $p<.001)$ and self-acceptance $(\beta=.31, p<.001)-$ while they were not related to autonomy. (Step 4) Consequently, in the assessment of the role of partner support as a possible mediator between prenatal concerns, a regression analysis was applied using environmental mastery and purpose in life as outcome variables.

The analyses showed that partner support fully mediated the relationship between pregnancy concerns and psychological well-being in two dimensions: environmental mastery and purpose in life. With partner support included in the regression equation, the $\beta$ weight for prenatal concerns becomes statistically insignificant for environmental mastery (see Figure 1).

When partner support was included in the regression equation, the $\beta$ weight for prenatal concerns became statistically insignificant for one of the dimensions of psychological well-being: purpose in life (see Figure 2).

\section{DISCUSSION}

One of the important aims of the current study was to examine relationships among prenatal concerns, received partner support and psychological well-

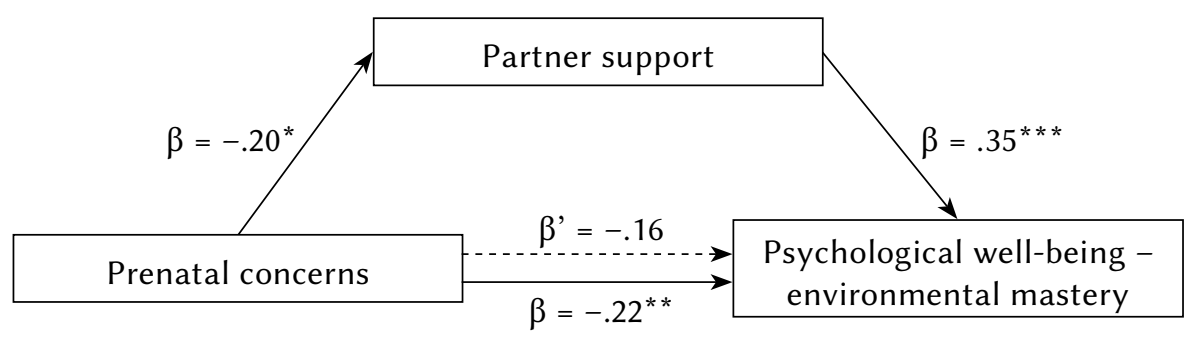

Note. ${ }^{*} p<.05,{ }^{* *} p<.01,{ }^{* * *} p<.001$.

Figure 1. Partner support as a mediator between prenatal concerns and psychological well-being (environmental mastery). 


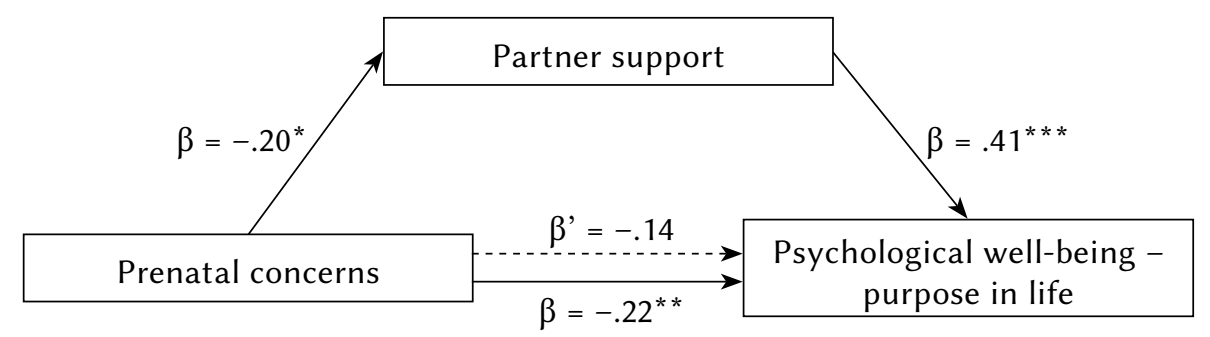

Note. ${ }^{*} p<.05,{ }^{* *} p<.01,{ }^{* * *} p<.001$.

Figure 2. Partner support as a mediator between prenatal concerns and psychological well-being (purpose in life).

being. Partner support was shown to be the strongest predictor of psychological well-being in five domains: environmental mastery, purpose in life, personal growth, positive relations with others and self-acceptance. The presented analyses correspond to recent findings regarding the impact of social support, particularly that received from a pregnant woman's partner, on her health and well-being (Zachariah, 1996; Dunkel-Schetter \& Brooks, 2009; Rini et al., 2006).

Pregnancy and motherhood are significant life events that, depending on how they are assessed, can become a source of stress, worries and concerns for women awaiting their child's birth. According to recent studies, a worry related to the course of pregnancy, particularly concerns about one's own health and the child's health, is common among pregnant women and may be particularly intense in some cases (Fava et al., 1990). This is especially true in the case of women who experience severe stress due to highrisk pregnancy or former obstetric failures (Koss, Rudnik, \& Bidzan, 2014). Gourounti et al. (2013) proved that prenatal anxiety, prenatal concerns and worry are predictors of depression in women in the prenatal and postnatal periods.

In addition, our research confirmed the negative prediction of prenatal concerns about the well-being of pregnant women in two aspects: environmental mastery and purpose in life. This means that increased concerns regarding the course of pregnancy and labor, worries concerning the child's health, and worries regarding the assessment of biological and psychological changes (which take place in the course of pregnancy, during childbirth and in the early postpartum period) can have a direct negative effect on some aspects of women's psychological well-being. Women can experience difficulties in determining their life purpose and direction, problems regarding beliefs about the fulfillment of important life tasks, and difficulties concerning beliefs about the ability to cope with the world.

Considering the exploratory character of our research, it was difficult to find other studies including a similar set of variables. However, certain similar relationships between the selected variables and psychological well-being were observed in some of the previous studies. Our results are consistent with previous research findings which suggest that social support and life stress are significant predictors of pregnant women's psychological well-being (Zachariah, 1996). The results reported by Cox, Eaton, Ekas, and Van Enkevort (2015) show that the psychological health for mothers of children with autism spectrum disorder is associated with their concerns about child mortality. According to Biehle and Mickelson (2011), it is essential to examine perinatal worries in parents because their concerns about childbirth and frequency of such worries predict worse well-being of mothers and fathers, which may result in lower relationship satisfaction.

It is worth emphasizing in the context of our mediation analyses that partner support fully mediated the relationship between pregnancy concerns of the pregnant women and their psychological well-being in two dimensions: environmental mastery and purpose in life. This means that for the pregnant women who receive support from their partners prenatal concerns cease to have a significant impact on their beliefs about the meaning of life and the feeling of having fulfilled important life tasks, as well as on their beliefs regarding their ability to cope with the world. Hence, received partner support can mitigate to a considerable degree the negative impact of women's concerns on some aspects of their well-being. This result is consistent with the recent research findings of other researchers. For example, it was found (Aktan, 2012; Li, Zeng, Zhu, Cui, \& Li, 2016) that social support is a positive mediator for antenatal depressive and anxiety symptoms, and pregnant women who receive social support could be protected from stressful events (Reid \& Taylor, 2015).

There is yet another interesting observation made in the course of our study; namely, prenatal concerns of the participants proved to be a negative predictor of partner support. Hence, this may indicate the partner's difficulties in coping with the pregnant woman's prenatal concerns, and insufficient abilities of men to detect these concerns and to respond accurately by providing support to the woman. Another explanation of this negative correlation between the
Partner support as a mediator of the relationship 
Michalina Ilska, Hanna

Przybyła-Basista woman's concerns and the support she received from her partner may be linked to the said support being viewed by women as unsatisfactory, ineffective or inadequate. These results meet the need for the currently undertaken studies on the conceptualization of the notion of social support effectiveness to be further expanded (Rini et al., 2006). The problem of partner support effectiveness seems highly important both for the sake of the pregnant woman's well-being and the potential impact of this assessment on the satisfaction with the marriage or partnership. For instance, the research conducted by Gourounti et al. (2014) shows a negative correlation between the satisfaction with a relationship and pregnant women's concerns.

The fact that prenatal concerns proved to be a negative predictor of partner support can be explained by the social support deterioration model (Kaniasty \& Norris, 2012), according to which in a situation of severe prolonged stress an individual makes a negative assessment of the source of available social support. In the event of an extremely stressful situation, the social support is mobilized. However, if the impact of a given stressor is prolonged, support resources decline (Kaniasty \& Norris, 2012). Among the reasons for received support not always playing a positive role one can list inadequacy of the form of support in relation to needs, improper source of support, as well as a threat to one's self-esteem (Kaniasty \& Norris, 2012). Further longitudinal studies would be helpful in confirming this hypothesis.

In terms of development, anticipating one's first child is a sensitive moment of exceptional importance for the entire family. Overcoming a potential developmental crisis related to this period calls for redefining recent social and familial roles, and moving to a new stage of family life with new tasks and objectives determined for the family. It is therefore a challenging period both for a couple and their relationship. The concerns that the woman experiences at that time can cause additional intensification of ambivalent emotions pertaining to the positive end of pregnancy and a satisfying completion of the transition to parenthood. These concerns may have adverse implications for both the pregnant woman and her partner, who may experience difficulties related to coping with the situation or provide support in a skillful manner.

Further studies should account for a more in-depth analysis of partner support by means of expanding the choice of instruments for measuring this variable. We consider that it would be appropriate to include investigation of social support effectiveness and to apply more specific instruments for measuring received support in intimate relationships. Moreover, many conclusions could be confirmed by means of collection of longitudinal data with repeated measures. Future research on the role of partner support in shaping the psychological well-being of pregnant women should also account for specific contexts such as high-risk pregnancy and a history of miscarriage or previous obstetric complications. This is particularly important for women exposed to negative emotions of high intensity during pregnancy. These shortcomings undoubtedly limit the conclusions of our study.

\section{CONCLUSIONS}

Social support, particularly partner support obtained by pregnant women, remains a frequently explored field of study. On the one hand, social support has been proven as significant for the physical and psychological health and well-being of pregnant women (and indirectly of their children). On the other, the complexity of the social support phenomenon does not allow for a more in-depth and conclusive understanding of the support mechanism. In other words, at present it is less important to collect evidence for the beneficial results of support (and, e.g., to seek simple correlations) than to seek answers to the questions "how does this mechanism work?" and "when is it efficient?".

Based on the conducted study, the following conclusions can be drawn:

1. Partner support was the strongest predictor of psychological well-being in the following five domains: environmental mastery, purpose in life, personal growth, positive relations with others and self-acceptance.

2. Our study proved received partner support to fully mediate the relationship between pregnancy concerns of pregnant women and their psychological well-being in two dimensions: environmental mastery and purpose in life.

The presented analyses back up findings of recent studies on the significance of social support, particularly partner support, for the health and well-being of a pregnant woman. They also provide new valuable conclusions. Our study proves that received partner support was a significant mediator in the relationship between concerns of pregnant women and some important areas of their psychological well-being. This means that owing to the support received by pregnant women from their partners, prenatal concerns cease to be statistically significant for the women's beliefs about the meaning of life, their feelings of having fulfilled important life tasks, as well as their beliefs about their ability to cope with the world.

Pregnant women often worry about various aspects of the transition to parenthood, pregnancy, the baby's health, money, possibilities of taking up work in the future and generally potential changes in the marital and family relationships, as well as in the personal life of women once the baby is born. Our results show that women during pregnancy, especially 
in the second and third trimester, need greater and more effective support from their partners to control emotions related to certain aspects of psychological well-being. Detailed analyses of the obtained results may help practitioners (e.g. psychologists, midwives) to pay more attention to specific worries of pregnant women. By linking the symptoms of such concerns with the risk of lowering psychological well-being of pregnant women the practitioners should acknowledge the positive role of partner support.

\section{RefERENCES}

Accortt, E. E., Cheadle, A., \& Dunkel-Schetter, C. (2015). Prenatal depression and adverse birth outcomes: An updated systematic review. Maternal and Child Health Journal, 19, 1306-1337.

Aktan, N. M. (2012). Social support and anxiety in pregnant and postpartum women: A secondary analysis. Clinical Nursing Research, 21, 183-194.

Baron, R. M., \& Kenny, D. A. (1986). The moderator-mediator variable distinction in social psychological research: Conceptual, strategic, and statistical considerations. Journal of Personality and Social Psychology, 51, 1173-1182.

Bidzan, M., Bieleninik, Ł., Zadolska, A., \& Salwach, D. (2009). Bond with a child in the prenatal period in case of prematurely born children. In K. Turowski (ed.), Wellness and success (pp. 35-54). Lublin: NeuroCentrum.

Biehle, S. N., \& Mickelson, K. D. (2011). Worries in expectant parents: Its relation with perinatal well-being and relationship satisfaction. Personal Relationships, 18, 697-713.

Bielawska-Batorowicz,E.,\&Kossakowska-Petrycka,K. (2006). Depressive mood in men after the birth of their offspring in relation to a partner's depression, social support, father's personality and prenatal expectations. Journal of Reproductive and Infant Psychology, 24, 21-29.

Bieleninik, Ł., Preis, J., \& Bidzan, M. (2010). Conditions of the emotional bond with a child in the prenatal period in case of multifetal and unifetal pregnancies. Perinatologia, Neonatologia i Ginekologia, 3, 223-231.

Cheng, C., \& Pickler, R. H. (2010). Maternal psychological well-being and salivary cortisol in late pregnancy and early post-partum. Stress and Health, 26, 215-224.

Cohen, S., \& Wills, T. A. (1985). Stress, social support, and the buffering hypothesis. Psychological Bulletin, 98, 310-357.

Collins, N. L., Dunkel-Schetter, C., Lobel, M., \& Scrimshaw, S. C. (1993). Social support in pregnancy: Psychosocial correlates of birth outcomes and postpartum depression. Journal of Personality and Social Psychology, 65, 1243-1258.
Cox, C. R., Eaton, S., Ekas, N. V., \& Van Enkevort, E. A. (2015). Death concerns and psychological well-being in mothers of children with autism spectrum disorder. Research in Developmental Disabilities, 45-46, 229-238.

DaCosta, D., Larouche, J., Dritsa, M., \& Brender, W. (1999). Variations in stress levels over the course of pregnancy: Factors associated with elevated hassles, state anxiety and pregnancy-specific stress. Journal of Psychosomatic Research, 47, 609-621.

Dibaba, Y., Fantahun, M., \& Hindin, M. J. (2013). The association of unwanted pregnancy and social support with depressive symptoms in pregnancy: Evidence from rural Southwestern Ethiopia. BMC Pregnancy and Childbirth, 13, 135. doi: 10.1186/1471-2393-13-135

Diener, E., Lucas, R. E., \& Oishi S. (2012). Dobrostan psychiczny. Nauka o szczęściu i zadowoleniu z życia [Subjective well-being: The science of happiness and life satisfaction]. In J. Czapiński (ed.), Psychologia Pozytywna. Nauka o szczęściu, zdrowiu, sile i cnotach czlowieka [Positive psychology. The science of happiness, health, power and human merits] (pp. 35-50). Warszawa: Wydawnictwo Naukowe PWN.

DiPietro, J. A. (2004). The role of prenatal maternal stress in child development. Current Directions in Psychological Science, 17, 71-74.

Dulude, D., Wright, J., \& Belanger, C. (2000). The effects of pregnancy complications on the parental adaptation process. Journal of Reproductive and Infant Psychology, 18, 5-20.

Dunkel-Schetter, C., \& Brooks, K. (2009). The nature of social support. In H. T. Reis \& S. Sprecher (eds.), Encyclopedia of Human Relationships (pp. 15651570). Thousand Oaks, Ca: Sage.

Dunkel-Schetter, C., Sagrestano, L. M., Feldman, P., \& Killingsworth, C. (1996). Social support and pregnancy. In G. R. Pierce, B. R. Sarason, \& I. G. Sarason (eds.), Handbook of social support and the family (pp. 375-412). New York: Plenum Press.

Dunkel-Schetter, C., \& Tanner, L. (2012). Anxiety, depression and stress in pregnancy: implications for mothers, children, research, and practice. Current Opinions of Psychiatry, 25, 141-148.

Dyrdal, G. M., Røysamb, E., Bang Nes, R., \& Vittersø, J. (2010). Can a happy relationship predict a happy life? A population-based study of maternal well-being during the life transition of pregnancy, infancy, and toddlerhood. Journal of Happiness Studies, 12, 947-962.

Fava, G. A, Grandi, S., Michelacci, L., Saviotti, F., Conti, S., Bovicelli, L., Trombini, G., \& Orlandi, C. (1990). Hypochondriacal fears and beliefs in pregnancy. Acta Psychiatrica Scandinavica, 82, 70-72.

Feldman, P. J., Dunkel-Schetter, C., Sandman, C. A., \& Wadhwa, P. D. (2000). Maternal social support
Partner support as a mediator of the relationship 
Michalina Ilska, Hanna

Przybyła-Basista predicts birth weight and fetal growth in human pregnancy. Psychosomatic Medicine, 62, 715-725.

Ghosh, J. K., Wilhelm, M. H., Dunkel-Schetter, C., Lombardi, C. A., \& Ritz, B. R. (2010). Paternal support and preterm birth, and the moderation of effects of chronic stress: a study in Los Angeles county mothers. Archives of Women's Mental Health, 13, 327-338.

Gourounti, K., Anagnostopoulos, F., \& Lykeridou, K. (2013). Coping strategies as psychological risk factor for antenatal anxiety, worries, and depression among Greek women. Archives of Women's Mental Health, 16, 353-361. doi: 10.1007/s00737-013-0338-y

Gourounti, K., Anagnostopoulos, F., \& Sandall, J. (2014). Poor marital support associate with anxiety and worries during pregnancy in Greek pregnant women. Midwifery, 30, 628-635. doi: 10.1016/j.midw.2013.10.008

Guardino, C. M., \& Dunkel-Schetter, C. (2014). Coping during pregnancy: a systematic review and recommendations. Health Psychology Review, 8, 70-94.

Hobfoll, S. (2002). Social and psychological resources and adaptation. Review of General Psychology, 6, 307-324.

Ilska, M., Kołodziej-Zaleska, A., \& Ilski, A. (2015). Prenatal concerns of high-risk and low-risk pregnant women: an analysis of the impact of risk factors and protective factors. Ginekologia i Potożnictwo Medical Project, 2, 61-70.

Ilska, M., \& Przybyła-Basista, H. (2014). Measurement of women's prenatal attitudes toward maternity and pregnancy and analysis of their predictors. Health Psychology Report, 2, 176-188.

Ilska, M., \& Przybyła-Basista, H. (2015). Kultura wizualna a kształtowanie się rodzicielstwa w prenatalnym okresie rozwoju [Visual culture and parenting formation in the prenatal period]. Chowanna, 2, 161-181.

Jesse, D. E., Kim, H., \& Herndon, C. (2014). Social support and self-esteem as mediators between stress and antepartum depressive symptoms in rural pregnant women. Reasearch in Nursing \& Health, 37, 241-252.

Kaniasty, K., \& Norris, F. H. (2012). „Wzlot i upadek utopii”: mobilizacja i deterioracja wsparcia społecznego w sytuacjach klęsk żywiołowych [The rise and fall of utopia: Mobilization and deterioration of social support in the aftermath natural disasters]. In H. Sęk \& R. Cieślak (eds.), Wsparcie społeczne, stres $i$ zdrowie [Social support, stress and health] (pp. 123-138). Warszawa: Wydawnictwo Naukowe PWN.

Kaźmierczak, M., Kiełbratowska, B., \& Karasiewicz, K. (2015). The other side of the mirror - the role of partner's empathy in transition to parenthood. Health Psychology Report, 3, 150-157.

Keyes, C. L. M., Shmotkin, D., \& Ryff, C. D. (2002). Optimizing well-being: The empirical encounter of two traditions. Journal of Personality and Social Psychology, 82, 1007-1022.

Koss, J., Rudnik, A., \& Bidzan, M. (2014). Experiencing stress and the obtained social support among women with high-risk pregnancies. Preliminary report. Family Forum. Problemy Wspótczesnej Rodziny, 4, 183-202.

Krok, D. (2009). Religijność a jakość życia w perspektywie mediatorów psychospotecznych [Religiousness and quality of life from the perspective of psychosocietal mediators]. Opole: WT UO.

Lee, S., Ayers, S., \& HIden, D. (2012). Risk perception of women during high risk pregnancy: A systematic review. Health, Risk \& Society, 14, 511-531.

Li, Y., Zeng, Y., Zhu, W., Cui, Y., \& Li, J. (2016). Path model of antenatal stress and depressive symptoms among Chinese primipara in late pregnancy. BMC Pregnancy and Childbirth, 16, 180.

Lobel, M., Cannella, D. L., Graham, J. E., DeVincent, C., Schneider, J., \& Meyer, B. A. (2008). Pregnancy-specific stress, prenatal health behaviors, and birth outcomes. Health Psychology, 27, 604-615.

Łuszczyńska, A., Kowalska, M., Mazurkiewicz, M., \& Schwarzem, R. (2006). Berlin Social Support Scales (BSSS): Polish version of BSSS and preliminary results on its psychometric properties. Studia Psychologiczne, 44, 17-27.

Mass, A., Vreeswijk, C., de Cock, E., Rijk, C., \& van Bakel, H. (2012). "Expectant Parents": Study protocol of a longitudinal study concerning prenatal (risk) factors and postnatal infant development, parenting, and parent-infant relationships. $B M C$ Pregnancy and Childbirth, 12, 46. Retrieved from: http://www.biomedcentral.com/1471-2393/12/46

Melender, H. L., \& Lauri, S. (1999). Fears associated with pregnancy and childbirth - experiences of women who have recently given birth. Midwifery, 15, 177-182.

Nishimura, A., Fujita, Y., Katsuta, M., Ishihara, A., \& Ohashi, K. (2015). Paternal postnatal depression in Japan. BMC Pregnancy and Childbirth, 15, 128. doi: 10.1186/s12884-015-0552-x

Norris, F. H., \& Kaniasty, K. (1996). Received and perceived social support in times of stress: A test of the social support deterioration deterrence model. Journal of Personality and Social Psychology, 71, 498-511.

Oakley, A. (1988). Is social support good for the health of mothers and babies? Journal of Reproductive and Infant Psychology, 6, 3-21.

Pawlicka, P., Chrzan-Dętkoś, M., \& Lutkiewicz, K. (2013). Prężność psychiczna przyszłych matek oraz kolejność ciąży jako moderatory budowania więzi z nienarodzonym jeszcze dzieckiem [Resilience of future mothers and order of pregnancies as moderators of building reationship with the unborn child]. Family Forum, 3, 139-152. 
Puente, C. P., Monge, F. J. C., Abella'n, I. C., \& Morales, D. M. (2011). Effects of personality on psychiatric and somatic symptoms in pregnant women: The role of pregnancy worries. Psychology of Women Quarterly, 35, 293-302.

Reid, K. M., \& Taylor, M. G. (2015). Social support, stress, and maternal postpartum depression: A comparison of supportive relationships. Social Science Research, 54, 246-262.

Rini, C., Dunkel-Schetter, C., Hobel, C. J., Glynn, L. M., \& Sandman, C. A. (2006). Effective social support: Antecedents and consequences of partner support during pregnancy. Personal Relationships, 13, 207-229.

Rini, C., Killingsworth, C., Dunkel-Schetter, C., Wadhwa, P. D., \& Sandman, C. A. (1999). Psychological adaptation and birth outcomes: The role of personal resources, stress, and sociocultural context in pregnancy. Health Psychology, 18, 333-345.

Ritter, C., Hobfoll, S. E., Stevan, E., Lavin, J., Cameron, R., \& Hulsizer, M. R. (2000). Stress, psychosocial resources, and depressive symptomatology during pregnancy in low-income, inner-city women. Health Psychology, 19, 576-585.

Ryff, C. D. (1989). Happiness is everything, or is it? Explorations on the meaning of psychological well-being. Journal of Personality and Social Psychology, 57, 1059-1081.

Ryff, C. D., \& Keyes, C. L. M. (1995). The structure of psychological well-being revisited. Journal of Personality and Social Psychology, 69, 719-717.

Sęk, H., \& Cieślak, R. (2012). Wsparcie społeczne sposoby definiowania, rodzaje i źródła wpsarcia, wybrane koncepcje teoretyczne [Social support - ways of defining, the types and sources of support, selected theoretical concepts]. In H. Sęk \& R. Cieślak (eds.), Wsparcie spoteczne, stres i zdrowie [Social support, stress and health] (pp. 11-29). Warszawa: Wydawnictwo Naukowe PWN.

Sieber, S., Germann, N., Barbir, A., \& Ehlert, U. (2006). Emotional well-being and predictors of birth-anxiety, self-efficacy, and psychosocial adaptation in healthy pregnant women. Acta Obstericia et Gynecologica, 85, 1200-1207.

Smoktunowicz, E., Cieślak, R., \& Żukowska, K. (2013). Rola wsparcia społecznego w kontekście stresu organizacyjnego oraz zaangażowania w pracę. Studia Psychologiczne, 51, 25-37.

Stapleton, L. R. T., Westling, E., Rini C., Glynn, L. M., Hobel, C. J., \& Sandman, C. A. (2012). Perceived partner support in pregnancy predicts lower maternal and infant distress. Journal of Family Psychology, 26, 454-463.

Yali, A. M., \& Lobel, M. (2002). Stress-resistance resources and coping in pregnancy. Anxiety, Stress and Coping, 15, 289-309.

Yim, I. S., Tanner Stapleton, L. R., Guardino, C. M., Hahn-Holbrook, J., \& Dunkel Schetter, C. (2015). Biological and psychosocial predictors of postpar- tum depression: Systematic review and call for integration. Annual Review of Clinical Psychology, 11, 99-137.

Zachariah, R. (1996). Predictors of psychological well-being of women during pregnancy: Replication and extension. Journal of Social Behavior \& Personality, 11, 127-140.
Partner support as a mediator of the relationship 